\title{
TRADITIONAL COMPLEMENTARY AND ALTERNATIVE MEDICINE: KNOWLEDGE, ATTITUDES AND PRACTICES OF HEALTH CARE WORKERS IN HIV AND AIDS CLINICS IN DURBAN HOSPITALS
}

\author{
Nozuko P. Mbutho ${ }^{1}{ }^{*}$ Nceba Gqaleni ${ }^{2}$ and Charmaine M. Korporaal ${ }^{1}$ \\ ${ }^{1}$ Department of Chiropractic and Somatology, Durban University of Technology, ${ }^{2}$ Traditional Medicine \\ Laboratory, University of KwaZulu-Natal, South Africa \\ *Email: gqalenin@ukzn.ac.za
}

\begin{abstract}
Traditional complementary and alternative medicine (TCAM) has been reported to be commonly used among individuals with HIV and AIDS disease. However a lack of communication between health care workers (HCWs) and patients as well as between HCWs and TCAM practitioners has been identified as one of the challenges that may adversely affect treatment of HIV and AIDS patients. With improved and sustained communication HCWs, patients and TCAM practitioners would be able to make informed decisions with regards to best treatment practices based on the knowledge of what is safe, effective and what is not. In order to establish a baseline understanding of the current status of interaction and communication between HCWs and TCAM profession in Durban, South Africa, the purpose of the study was to investigate the knowledge, attitudes and practices of HCWs in the HIV and AIDS clinics towards TCAM professions. Data was collected by means of anonymous self-administered questionnaire which was distributed to HCWs in the HIV and AIDS clinics. Out of 161 HCWs in the HIV and AIDS clinics 81 HCWs returned the questionnaires resulting in $50 \%$ response rate. The results showed that participants did not possess a basic knowledge of TCAM. Out of 81 participants 23 (28\%) scored zero in a true or false knowledge assessment question.
\end{abstract}

Keywords: Traditional Complementary and Alternative medicine, Health care workers, knowledge attitude and practices, HIV and AIDS.

\section{Introduction}

Usage of TCAM by the public has increased drastically (Willison et al., 2004) and among people with HIV and AIDS (Achilles et al., 1999) irrespective of whether it is through evidence based national health systems or through private access by patients (White, 2000). It is estimated that in the United States of America (USA) TCAM is used by approximately one-third of the population (Willison, 2004). In European countries where statistics are available it is estimated that TCAM treatment is being utilized by $20-50 \%$ of the population and in the United Kingdom (UK) this may amount to one in four people (Botting, 1997). Furthermore up to $80 \%$ of the people in developing counties rely on TCAM specifically traditional medicine for their primary health care due to cultural traditions or lack of alternative (Chandy, 2004). Communities such as aboriginal people, Chinese community and Indian community consider TCAM not as an alternative but as part of their cultural heritage and is perceived as standard care (Achilles et al., 1999).

This trend seems to be mirrored in South Africa, where the Department of Health estimates that there are 200000 traditional healers in the country that consult for variety of traditional medicines and that there are 3622 allied health practitioners that are registered for variety of complementary alternative medicines (Gqaleni et al., 2007). Moreover internationally it has been found that up to 79\% of HIV patients utilize TCAM (Dhalla et al., 2006; London et al., 2003). There are several implications with regards to increase TCAM utilization including:

1. Patients might not tell their doctors or health care providers that they are utilizing TCAM, this lack of communication may increase a potential risk for that patient who do not inform their doctors about their use of TCAM as these patients may be exposed to adverse treatment effects when being treated in non-TCAM setting (Chandy, 2004).

2. The lack of communication is further negatively impacted by the fact that patients actually do not make informed choices with regards to the medical treatment choices available for their condition. The information that they have is fragmented, and often times unreliable and incomplete due to lack of communication (WHO, 2008).

Despite the several challenges with regards to use of TCAM and conventional medicine, patients still seek TCAM, therefore it is imperative that as the public increases its demand for TCAM it is necessary for accurate sources of information on TCAM to be readily available to the public. It seems logical that HCWs can make a significant contribution in assisting patients to make informed decisions regarding TCAM (Brolinson, 2001; Long, 2001) It is however unknown what the current level of TCAM knowledge of HCWs in South Africa (SA) is. Therefore, to address this gap, this study aimed at assessing the knowledge, attitude and practices of HCWs towards TCAM. 


\section{Methods}

This cross sectional study was conducted in 2009 in ten HIV and AIDS clinics located within state hospitals at eThekwini district, Durban to investigate:

- $\quad$ HCWs' knowledge of TCAM and TCAM legislation.

- HCWs' attitudes towards use of TCAM.

- $\quad$ HCWs' personal practices of TCAM

- HCWs' professional practices of TCAM

- $\quad$ HCWs willingness to receive TCAM training.

- $\quad$ Factors associated (e.g. demographics, knowledge, attitudes) with the use of TCAM.

The 161 health care workers working in the HIV and AIDS clinics made up the study group. An anonymous self-administered questionnaire was used to collect data of the HCWs responses. The questionnaire covered four main areas: Demographic profile of the HCWs; their knowledge of TCAM and TCAM legislation in SA; their personal and professional use of TCAM; their attitudes towards TCAM. Specific TCAM therapies were identified in the questionnaire and included those that are legislated in South Africa. The questionnaire was modelled on different questionnaires that were utilised in previous international and national studies (Lewith et al., 2001; Risberg et al., 2004; Truter, 2005). The authors who created the questionnaires were acknowledged in the study as they developed and piloted these questionnaires, however with the contextualization of the questionnaire to the context of this study questions were not utilized directly from these previous questionnaires.

After questionnaire development a focus group was conducted for the purpose of ensuring that all possible avenues of information pertinent to the study had been included in addition to ruling out ambiguity. The questionnaire was then piloted at the Durban University of Technology HIV and AIDS clinic.

\section{Results Response Rate}

Of the 161 HCWs, 81 (50\%) completed the questionnaire. There were 50 refusals and 30 non-contacts.

\section{Demographic Profile}

Table 1 shows the demographic profile of the participants. They were comprised of $85.2 \%$ female and $14.8 \%$ male. The participant age group ranged from 19 to 62 years. Only one person from Australia participated and the rest of the participants were from South Africa. Seventy four percent of the participants were African, 18.5\% were Indian, 3.7\% were Coloured, and 2.5\% were White. Majority of the participants' home language was isiZulu (67.9\%), followed by English (24.7\%), isiXhosa (4.9\%), Sesotho and Afrikaans (1.2\%). The bulk of the participants were nurses (47.50\%), followed by lay counselors (25\%), doctors (8.5\%), psychologists (2.5\%), social workers (1.2\%) and other (14.8\%). Others included two pharmacists, five data capturers, one auxiliary service officer, one phlebotomist and one treatment literacy technician. Participants had some type of a degree (19.6\%), $28.7 \%$ had a diploma, $37.8 \%$ had a college certificate and only $13.6 \%$ had standard ten (grade 12 equivalent) qualifications. The majority of the qualifications were obtained from a university (40\%), hospitals (27\%), college (10.4\%), and nursing school (6.3\%), and high school (10.4\%), university of technology (6.3\%). The participants had an average of 2.83 years working experience in the HIV and AIDS clinic and an average of 10.55 years working experience in the health field. Of the 81 participants, $92.4 \%$ were working full time in the HIV and AIDS clinic, only 5.1\% were part-time workers, and $2.5 \%$ were volunteers.

\section{Participant's Knowledge of TCAM}

The participants were asked to rate their knowledge of TCAM professions. A Likert-type scale was utilized to address the responses with 4 being (very good), 3 (good), 2 (fair), and 1(poor). As a result, most participants rated their own knowledge of traditional African medicine (63.3\%), therapeutic aromatherapy (27\%), homeopathy (46.6\%), traditional Chinese medicine (62.7\%), unani-tibb (83.3\%), naturopathy (54.5\%), osteopathy (68.5), acupuncture (44.8\%), ayurveda (64.2\%), phytotherapy $(69.6 \%)$ and chiropractic (57.1\%) as 'poor'. Other participants rated their knowledge of therapeutic massage and therapeutic reflexology 'poor' to 'fair'. Knowledge of massage was rated 'fair to very good' by the majority (60.7\%) of the participants.

To assess HCWs' knowledge of TCAM a basic true or false questions were asked. The questions asked about TCAM included definitions, origin of TCAM professions, function of the TCAM professions and where TCAM qualifications were offered. The results are indicated in Table 2.

Most participants seemed to be more knowledgeable about massage, but they could not respond to the more in-depth information about massage. In general most participants did not have the basic knowledge of the TCAM professions. Out of 81 participants, 23 scored zero (28\%); this indicates that they had no knowledge of TCAM. The maximum score was 76.67\%. The participants had an average score of $20-45 \%$. This indicates that in general participants had limited knowledge of TCAM. 
Table 1: Demographic characteristics of the participants

\begin{tabular}{|c|c|c|}
\hline Characteristics & Total sample $(n=81)$ & Percentages (\%) \\
\hline \multicolumn{3}{|l|}{ Gender } \\
\hline$\overline{\text { Male }}$ & 12 & $14.8 \%$ \\
\hline Female & 69 & $85.2 \%$ \\
\hline Age (mean) & 73 & $37.84 \mathrm{sd}(10.707)$ \\
\hline \multicolumn{3}{|l|}{ Citizenship } \\
\hline South African & 80 & $98.8 \%$ \\
\hline Australian & 1 & $1.2 \%$ \\
\hline \multicolumn{3}{|l|}{ Home language } \\
\hline Afrikaans & 1 & $1.2 \%$ \\
\hline English & 20 & $24.7 \%$ \\
\hline IsiXhosa & 4 & $4.9 \%$ \\
\hline IsiZulu & 55 & $67.9 \%$ \\
\hline Sesotho & 1 & $1.2 \%$ \\
\hline \multicolumn{3}{|l|}{ Current profession } \\
\hline Doctors & 7 & $8.8 \%$ \\
\hline Nurses & 38 & $47.5 \%$ \\
\hline Lay counselor & 20 & $25 \%$ \\
\hline Psychologists & 2 & $2.5 \%$ \\
\hline Social worker & 1 & $1.3 \%$ \\
\hline Others & 12 & $15 \%$ \\
\hline \multicolumn{3}{|l|}{ Hiqhest qualification } \\
\hline Degree & 13 & $19.6 \%$ \\
\hline Diploma & 19 & $28.7 \%$ \\
\hline College certificate & 25 & $37.8 \%$ \\
\hline Standard 10 & 9 & $13.6 \%$ \\
\hline \multicolumn{3}{|l|}{ Where qualification was obtained } \\
\hline University & 19 & $(40 \%)$ \\
\hline Hospitals & 13 & $(27 \%)$ \\
\hline College & 5 & $(10.4 \%)$ \\
\hline Nursing school & 3 & $(6.3 \%)$ \\
\hline High school & 5 & (10.4\%) \\
\hline University of Technology & 3 & $(6.3 \%)$ \\
\hline \multicolumn{3}{|l|}{ TCAM certificates } \\
\hline Yes & 3 & $2.8 \%$ \\
\hline No & 76 & $96.2 \%$ \\
\hline Experience (HIV and AIDS) clinic (Mean) & 75 & $2.83 \mathrm{sd}(2.67)$ \\
\hline Experience (Health field) (Mean) & 73 & 10.55 sd (9.51) \\
\hline \multicolumn{3}{|l|}{ Race } \\
\hline$\overline{\text { African }}$ & 60 & $74.1 \%$ \\
\hline Coloured & 3 & $3.7 \%$ \\
\hline Indian & 15 & $18.5 \%$ \\
\hline Whites & 2 & $2.5 \%$ \\
\hline Others & 1 & $1.2 \%$ \\
\hline \multicolumn{3}{|l|}{ Work status } \\
\hline$\overline{\text { Full-time }}$ & 73 & $92.4 \%$ \\
\hline Part-time & 4 & $5.1 \%$ \\
\hline Volunteer & 2 & $2.5 \%$ \\
\hline
\end{tabular}


Table 2: An Assessment of the Basic Knowledge of CAM by Participants

\begin{tabular}{|c|c|c|c|c|c|c|}
\hline \multirow[t]{2}{*}{ Questions } & \multicolumn{2}{|c|}{ True } & \multicolumn{2}{|c|}{ False } & \multicolumn{2}{|c|}{ Don't know } \\
\hline & $\mathrm{n}$ & $\%$ & $\mathrm{n}$ & $\%$ & $\mathrm{n}$ & $\%$ \\
\hline 1. Acupuncture has been scientifically proven to relieve pain. (T) & 29 & $38.7 \%$ & 1 & $1.3 \%$ & 45 & $60.0 \%$ \\
\hline $\begin{array}{l}\text { 2. Acupuncture is a needling procedure that is used to address the flow of vital } \\
\text { energy within the meridians. }(\mathrm{T})\end{array}$ & 21 & $26.9 \%$ & 4 & $5.1 \%$ & 53 & $67.9 \%$ \\
\hline 3. Therapeutic massage is the manipulation of soft tissues. (T) & 36 & $46.8 \%$ & 3 & $3.9 \%$ & 38 & $49.4 \%$ \\
\hline 4. Therapeutic massage includes the following movements: Effleurage. (T) & 5 & $6.6 \%$ & 3 & $3.9 \%$ & 68 & $89.5 \%$ \\
\hline 5. Petrissage. $(\mathrm{T})$ & 5 & $6.5 \%$ & 3 & $3.9 \%$ & 69 & $89.6 \%$ \\
\hline 6. Therapeutic aromatherapy and herbal medicine is the same thing. (F) & 7 & $9.1 \%$ & 23 & $29.9 \%$ & 47 & $61.0 \%$ \\
\hline $\begin{array}{l}\text { 7. Therapeutic massage is a practice of using essential oils therapeutically to treat } \\
\text { wide range of problems. (F) }\end{array}$ & 33 & $42.9 \%$ & 8 & $10.4 \%$ & 36 & $46.8 \%$ \\
\hline 8. The following are essential oils: Olive oil.( F) & 33 & $41.8 \%$ & 5 & $6.3 \%$ & 41 & $51.9 \%$ \\
\hline 9. Rosemary. (T) & 38 & $48.7 \%$ & 2 & $2.6 \%$ & 38 & $48.7 \%$ \\
\hline 10. Chamomile. (T) & 35 & $44.9 \%$ & 3 & $3.8 \%$ & 40 & $51.3 \%$ \\
\hline 11. Grape seed oil. (F) & 25 & $33.3 \%$ & 7 & $9.3 \%$ & 43 & $57.3 \%$ \\
\hline 12. Reflexology and foot massage uses the same technique. (F) & 16 & $20.8 \%$ & 14 & $18.2 \%$ & 47 & $61.0 \%$ \\
\hline 13. Reflexology focuses on stimulating reflex points on the foot. (T) & 29 & $36.7 \%$ & 4 & $5.1 \%$ & 46 & $58.2 \%$ \\
\hline $\begin{array}{l}\text { 14. Because of their training chiropractors can focus on the following: Acupuncture. } \\
\text { (T) }\end{array}$ & 16 & $21.1 \%$ & 8 & $10.5 \%$ & 52 & $68.4 \%$ \\
\hline 15. Neuro-musculoskeletal system. (T) & 25 & $32.1 \%$ & 3 & $3.8 \%$ & 50 & $64.1 \%$ \\
\hline 16. Surgery. (F) & 13 & $16.7 \%$ & 12 & $15.4 \%$ & 53 & $67.9 \%$ \\
\hline 17. Homeopathy was developed by German physician Samuel Hahnemann. (T) & 11 & $14.3 \%$ & 2 & $2.6 \%$ & 64 & $83.1 \%$ \\
\hline $\begin{array}{l}\text { 18. Naturopath is a person who practices several TCAM and has a solid grounding } \\
\text { of medical science. }(\mathrm{T})\end{array}$ & 7 & $9.3 \%$ & 4 & $5.3 \%$ & 64 & $85.3 \%$ \\
\hline $\begin{array}{l}\text { 19. Homeopathy is offered in the following Universities of Technologies: Durban } \\
\text { University of Technology. (T) }\end{array}$ & 25 & $32.5 \%$ & 1 & $1.3 \%$ & 51 & $66.2 \%$ \\
\hline 20. Cape Town University of Technology. (F) & 21 & $26.9 \%$ & 2 & $2.6 \%$ & 55 & $70.5 \%$ \\
\hline 21. Medunsa. (F) & 15 & $19.2 \%$ & 5 & $6.4 \%$ & 58 & $74.4 \%$ \\
\hline 22. Traditional Chinese Medicine is sometimes referred to as Oriental Medicine. (T) & 17 & $22.1 \%$ & 4 & $5.2 \%$ & 56 & $72.7 \%$ \\
\hline $\begin{array}{l}\text { 23. Traditional Chinese Medicine is a system of health which includes: Herbal } \\
\text { therapies. }(\mathrm{T})\end{array}$ & 24 & $31.2 \%$ & 1 & $1.3 \%$ & 52 & $67.5 \%$ \\
\hline 24. Gynaecology. (F) & 13 & $16.9 \%$ & 10 & $13.0 \%$ & 54 & $70.1 \%$ \\
\hline 25. Nutritional therapies. (T) & 16 & $21.3 \%$ & 3 & $4.0 \%$ & 56 & $74.7 \%$ \\
\hline 26. Manipulation. (T) & 8 & $10.5 \%$ & 10 & $13.2 \%$ & 58 & $76.3 \%$ \\
\hline 27. Ayurveda is a traditional healing system which began in China. (F) & 4 & $5.2 \%$ & 12 & $15.6 \%$ & 61 & $79.2 \%$ \\
\hline 28. Phytotherapy is a western herbal medicine tradition. (T) & 9 & $11.7 \%$ & 7 & $9.1 \%$ & 61 & $79.2 \%$ \\
\hline $\begin{array}{l}\text { 29. Osteopathy is based on the belief that most diseases are related to problems in } \\
\text { the musculoskeletal system. }(\mathrm{T})\end{array}$ & 19 & $24.7 \%$ & 2 & $2.6 \%$ & 56 & $72.7 \%$ \\
\hline $\begin{array}{l}\text { 30. Homeopathic medicines work on the way you are feeling mentally, emotionally } \\
\text { and physically. (T) }\end{array}$ & 24 & $31.2 \%$ & 5 & $6.5 \%$ & 48 & $62.3 \%$ \\
\hline
\end{tabular}

$\mathbf{T}=$ True and $\mathbf{F}=$ False

\section{Knowledge of TCAM Legislation}

Most participants (78.9\%) stated that TCAM was not legislated in SA. Twelve participants out of 57 stated that TCAM was legislated but did not know by whom. Twenty four participants said they did not know if TCAM was legislated or not. It is therefore clear that these HCWs are not aware that TCAM is legislated in SA. 


\section{Willingness to Receive TCAM training}

Majority of the participants had not received formal TCAM training (91.1\%) (72 out of 79) and did not receive informal training (96.3\%). Fifty nine out of seventy nine participants (74.7\%) wanted TCAM training. Twenty out of seventy nine (25.3\%) did not want TCAM training. It is clear that majority of the HCWs are interested in TCAM training. Participants wanted to train mostly for Ayurveda (40.43\%), followed by aromatherapy (38.3\%), and massage (38.3\%). Most participants were not interested in unani-tibb training (21.28\%).

\section{Attitude Towards TCAM}

Participants were then asked to indicate their own view of TCAM. A Likert-type scale was utilized to address the responses in this question with 5 being (very positive), 4 (slightly positive), 3 (neutral), 2 (slightly negative), 1 (very negative) and 0 (don't know). As shown in Table 3, most participants felt they could not answer this question because they did not have a clear understanding of what TCAM was; hence 33.3\% said they did not know. Only a few were very negative towards TCAM (3.7\%) and some were slightly negative (4.9\%). Most of the participants were neutral (28.4\%), some were slightly positive (16.0\%), and very positive (13.6\%)

The questionnaire used dichotomous questions where the participants were asked to respond yes / no / don't know to attitude statements. If the participants chose a "no" response they were then asked to elaborate more.

With regards to safety and side effects of TCAM 78.8\% did not know if TCAM was safe or not, whereas 7.5\% said yes TCAM was safe and $13.8 \%$ said it was not safe. HCWs felt that there was no scientific validation of many TCAM interventions and that there are insufficient studies on South African patients to determine side effect profiles. Furthermore they felt that every medication has its own side effects. The HCWs were concerned that they had experiences with poorly trained TCAM practitioners. Some felt that TCAM had a complementary role. What is clear is that HCWs are not aware of the benefits of TCAM and that more research needs to be conducted as scientific evidence is the main concern to ensure safe and beneficial use of TCAM.

In response to the attitude statement that TCAM's main use is as a preventative medicine, most participants did not know whether it could be used mainly as preventative medicine or not (81\%), 8.9\% said yes TCAM's main use is as preventative medicine and $10.1 \%$ said no its main use is not only preventative. They felt that TCAM professions were preventative and curative for some diseases and that TCAM can also be used on acute illnesses and lastly that TCAM had a complementary role. Some of the themes that were evident when HCWs were asked if TCAM should only be used as a last resort when conventional medicine had nothing to offer were that TCAM has a complementary role. One of the participants stated that "in India TCAM is used first line, further in India 70\% of rural Indians use Ayurveda as first line treatment”. Some felt TCAM can help before trying other stronger medications. Majority (77.5\%) said they did not know if TCAM should be used as a last resort or not, 5\% said yes and $17.5 \%$ said no TCAM can also be used for other roles as well.

Although some HCWs believed that TCAM could be useful instead of repeat prescriptions (6.3\%), many others (13.9\%) reported that they felt that patients will not be treated properly in certain diseases, they stated that certain diseases required allopathic medicine. Furthermore HCWs felt that in case of HIV patients, ARVs are a lifelong treatment and are not to be mixed with other herbs. Some said that they think that conventional medicine is very important as there are ample studies and research to support it. Majority (79.7\%) said they did not know enough about attitude statement.

In reply to the following attitude statement: TCAM should only be used in minor ailments and not in treatment of more serious illnesses, $79.2 \%$ said they did not know, $10.4 \%$ said yes and $10.4 \%$ said no. HCWs felt that TCAM had a complementary role, can be used in conjunction with mainstream and that TCAM can serve a purpose in both minor and serious illnesses.

HCWs held both positive and negative attitudes when asked if they thought TCAM represented a confused medical treatment care. They felt that the traditional medicines can be useful if used correctly. More research and scientific evidence is needed though.

In response to the question whether they get annoyed if the patients use TCAM without telling them, there were positive and negative responses to the question. On the positive side , HCWs (23.7\%) felt that patients have right to choose their mode of care, some felt that they could not judge other people's beliefs, all they could do was to talk and reason with the patient and then advise them accordingly. Some felt that alternative medicine does have a place in health care. Some responded negatively (18.4\%) stating that they get annoyed if the patients do not tell them that they are using TCAM as there is a risk of drug-herb interaction, that the interaction can affect the accuracy of blood tests, and lastly that it might affect adherence to the prescribed drug and therefore lead to drug resistance. Majority said they did not know (57.9\%).

With regards to including TCAM to the current health system budget some HCWs felt that there is not enough funding available for conventional medicine and patients wanting TCAM therapies should pay for TCAM out of their own pockets. They also felt that because it is not scientifically validated by medical practitioners, it should not be included in the current budget system. Others felt that it would be good to create awareness and that communities will know that TCAM is important.

Many HCWs (20.8\%) reported that touch therapies are better as there is a lesser chance of overdosing; there are no side effects, no drug interaction as it is less harmless, and that touch therapies improve blood circulation. Others 5.2\% said they do not feel better with touch therapy rather than ingested therapy. They felt that there was invasion of privacy and that touch therapy will not work as the disease is already in the system. 
Table 3: Response to TCAM attitude statements

\begin{tabular}{|c|c|c|c|c|c|c|c|c|}
\hline \multirow[t]{2}{*}{ Attitude statements } & \multicolumn{2}{|c|}{ Yes } & \multicolumn{2}{|c|}{ No } & \multicolumn{2}{|c|}{ Don't know } & \multirow[b]{2}{*}{ Total } & \multirow[b]{2}{*}{ Missing } \\
\hline & $\mathrm{N}$ & $\%$ & $\mathrm{~N}$ & $\%$ & $\mathrm{n}$ & $\%$ & & \\
\hline TCAM is safe and has few side effects & 6 & $7.5 \%$ & 11 & $13.8 \%$ & 63 & $78.8 \%$ & 80 & 1 \\
\hline Used as preventative medicine & 7 & $8.9 \%$ & 8 & $10.1 \%$ & 64 & $81.0 \%$ & 79 & 2 \\
\hline TCAM can be dangerous & 17 & $21.3 \%$ & 5 & $6.3 \%$ & 58 & $72.5 \%$ & 80 & 1 \\
\hline TCAM used as last resort & 4 & $5.0 \%$ & 14 & $17.5 \%$ & 62 & $77.5 \%$ & 80 & 1 \\
\hline $\begin{array}{l}\text { TCAM can be used effectively instead of } \\
\text { repeated prescription }\end{array}$ & 5 & $6.3 \%$ & 11 & $13.9 \%$ & 63 & $79.7 \%$ & 79 & 2 \\
\hline TCAM Should only be used in minor ailments & 8 & $10.4 \%$ & 8 & $10.4 \%$ & 61 & $79.2 \%$ & 77 & 4 \\
\hline $\begin{array}{l}\text { TCAM represents a confused approach to } \\
\text { medical care }\end{array}$ & 4 & $5.3 \%$ & 9 & $11.8 \%$ & 63 & $82.9 \%$ & 76 & 5 \\
\hline $\begin{array}{l}\text { I am annoyed if patients do not tell me that } \\
\text { they use TCAM }\end{array}$ & 14 & $18.4 \%$ & 18 & $23.7 \%$ & 44 & $57.9 \%$ & 76 & 5 \\
\hline $\begin{array}{l}\text { TCAM should be made available in the } \\
\text { current Health system budget }\end{array}$ & 12 & $15.8 \%$ & 6 & $7.9 \%$ & 58 & $76.3 \%$ & 76 & 5 \\
\hline $\begin{array}{l}\text { TCAM works to restore the body's own } \\
\text { balance }\end{array}$ & 18 & $23.4 \%$ & 0 & $.0 \%$ & 59 & $76.6 \%$ & 77 & 4 \\
\hline I feel comfortable with touch Therapies & 16 & $20.8 \%$ & 4 & $5.2 \%$ & 57 & $74.0 \%$ & 77 & 4 \\
\hline
\end{tabular}

\section{Personal Practice of TCAM}

Nineteen out of 81 participants indicated that they personally used TCAM Majority of the participants stated that they used therapeutic aromatherapy (12.9\%) followed by therapeutic massage (9.68\%), then homeopathy, African traditional medicine and Ayuverda (8.06\%). naturopathy (1.61\%) was by few HCWs.

\section{Professional Practice of TCAM}

Only eight out of seventy nine participants (10.1\%) indicated that they refer patients to TCAM professions. Seventy one out of the seventy nine participants (89.9\%) stated that they did not refer patients to TCAM professions. Twenty four out of seventy nine participants (30.4\%) thought it was ethical to refer patients to TCAM, eight out of seventy nine participants (10.1\%) thought it was unethical to refer patients to TCAM and forty seven out of seventy nine participants (59.5\%) did not know if it was ethical or not to refer patients to TCAM professions. Twenty five out of seventy nine participants (31.6\%) thought it was ethical to practice TCAM as well as conventional medicine, ten out of seventy nine participants (12.7\%) thought it was unethical to practice TCAM as well as conventional medicine, forty four out of seventy nine participants (55.7\%) did not know if it was ethical or not to practice TCAM as well as conventional medicine.

The results also show that eight out of seventy seven participants (10.4\%) knew other health professionals who refer patients to TCAM professions, sixty nine out of seventy seven participants (89.6\%) did not know other health professionals who refer patients to TCAM practitioners. The HCWs were asked if they have referred patients to TCAM and in light of their responses they were asked to elaborate on their answers with reasons indicating why they did or did not refer. The responses from the participants who did not refer indicated the following areas of concern: limited knowledge of TCAM professions; limited knowledge of the benefit to the patient/ patient's condition; fear of drug interaction with TCAM therapies; fear of overdose and inability to recognize problems based on the foregoing and accessibility with regards to cost and geographic location.

\section{Factors associated with Personal Use of TCAM}

Table 4 shows that there was no significant association between most of demographics and personal use of TCAM, except for language. The chi-squared test indicated that there is a highly significant association $(\mathrm{p}=0.001)$ between the use of TCAM and home language of the participants, which may reflect the fact that most literature for TCAM therapies is available in English only. 
Table 4: Association between language and personal use of TCAM

\begin{tabular}{|c|c|c|c|c|c|}
\hline & & & \multicolumn{2}{|c|}{ Personal use of TCAM } & Total \\
\hline \multirow[t]{7}{*}{ Language } & Afrikaans & Count & 0 & 1 & 1 \\
\hline & English & Count & 9 & 11 & 20 \\
\hline & & \% within Language & $45.0 \%$ & $55.0 \%$ & $100.0 \%$ \\
\hline & isiZulu & Count & 48 & 7 & 55 \\
\hline & & \% within Language & $87.3 \%$ & $12.7 \%$ & $100.0 \%$ \\
\hline & Sesotho & Count & 1 & 0 & 1 \\
\hline & & \% within Language & $100.0 \%$ & $0 \%$ & $100.0 \%$ \\
\hline Total & & Count & 62 & 19 & 81 \\
\hline
\end{tabular}

Pearson Chi Squared $p=0.001$; Linear by Linear association $p=0.000$

\section{Factors Associated with Professional Use of TCAM}

The chi squared test show that there is an association $(p=0.000)$ between gender of the participants and their referral to TCAM. It therefore appears that male participants refer more than female participants, although the sample size is too small to draw firm conclusions.

Table 5: Association between gender and referral to TCAM

\begin{tabular}{|c|c|c|c|c|c|}
\hline & & & \multicolumn{2}{|c|}{ Referral to TCAM } & \multirow{2}{*}{$\begin{array}{l}\text { Total } \\
\text { No. }\end{array}$} \\
\hline & & & Yes & No & \\
\hline \multirow[t]{4}{*}{ Gender } & Female & Count & 3 & 65 & 68 \\
\hline & & \% within Gender & $4.4 \%$ & $95.6 \%$ & $100.0 \%$ \\
\hline & Male & Count & 5 & 6 & 11 \\
\hline & & \% within Gender & $45.5 \%$ & $54.5 \%$ & $100.0 \%$ \\
\hline \multirow[t]{2}{*}{ Total } & & Count & 8 & 71 & 79 \\
\hline & & \% within Gender & $10.1 \%$ & $89.9 \%$ & $100.0 \%$ \\
\hline
\end{tabular}

Pearson Chi-Squared test $p=0.000$ Fisher's exact $p=0.001$ Linear by Linear association $p=0.000$

The chi squared test is significant $(\mathrm{p}=0.002)$ indicating a relationship between current profession and referral to TCAM professions. It would seem that doctors refer more than nurses and more than the other HCWs. It is therefore likely that current profession may influence the HCW's professional practice of TCAM.

Table 6: Association between current profession and referral to TCAM

\begin{tabular}{|c|c|c|c|c|c|}
\hline & & & \multicolumn{2}{|c|}{ Referral to TCAM } & \multirow{2}{*}{$\begin{array}{l}\text { Total } \\
\text { No. }\end{array}$} \\
\hline \multirow{12}{*}{ Current Profession } & & & Yes & No & \\
\hline & Doctor & Count & 4 & 3 & 7 \\
\hline & & \% within Current profession & $57.1 \%$ & $42.9 \%$ & $100.0 \%$ \\
\hline & Nurse & Count & 2 & 35 & 37 \\
\hline & & \% within Current profession & $5.4 \%$ & $94.6 \%$ & $100.0 \%$ \\
\hline & Lay counselor & Count & 1 & 19 & 20 \\
\hline & & \% within Current profession & $5.0 \%$ & $95.0 \%$ & $100.0 \%$ \\
\hline & Psychologist & Count & 0 & 2 & 2 \\
\hline & & \% within Current profession & $0 \%$ & $100.0 \%$ & $100.0 \%$ \\
\hline & Social worker & Count & 0 & 1 & 1 \\
\hline & & \% within Current profession & $0 \%$ & $100.0 \%$ & $100.0 \%$ \\
\hline & Others (specify) & Count & 1 & 10 & 11 \\
\hline \multirow{3}{*}{ Total } & & \% within Current profession & $9.1 \%$ & $90.9 \%$ & $100.0 \%$ \\
\hline & & Count & 8 & 70 & 78 \\
\hline & & \% within Current profession & $10.3 \%$ & $89.7 \%$ & $100.0 \%$ \\
\hline
\end{tabular}

Pearson Chi-Squared test $\mathrm{p}=0.002$ Linear by linear association $\mathrm{p}=0.15$ 
Eight participants with the average mean age of 40 years referred patients to TCAM, while 63 participants with the mean age of 38.11 years did not refer patients to TCAM - the F test is significant indicating that there is a difference between the mean numbers of those who refer for different age groups. The participants who refer seem to be older $($ mean $=40)$ than those who did not refer $($ mean $=38.11)$.

\section{Discussion}

The findings in this study show that most of the participants had poor to fair knowledge of massage and reflexology and poor knowledge of the other TCAM professions listed in this study. In general participants had limited knowledge of TCAM and the majority had virtually no formal or systemic education or training about TCAM. This study shows that the lack of knowledge may be due to, lack of information in the workplace about TCAM; unavailability of TCAM policies in the workplace, lack of education in both the undergraduate and post-graduate programmes.

The results of this study are comparable with a study conducted in SA by Truter (2005) which showed that the pharmacy students at the University of Port Elizabeth had limited knowledge of TCAM. These results are also similar to those in the study by Uzun and Tan (2004) where nursing students also had limited knowledge although they seemed to have intermediate but very basic knowledge of massage. The results on knowledge also resemble studies by Chez, Jones and Crawford (2001); Dekeyser, Cohen, Wagner, (2001); Lewith et al. (2001); Brown et al, (2007) and Holroyd et al. (2008), where the participants had poor knowledge of TCAM.

Furthermore majority (78.9\%) of the HCWs were not aware that TCAM was legislated in SA. These findings are similar to the findings from Brown et al. (2007), where participants were asked if they were aware of the existence at the Izaak Walton Killam (IWK) Health Center of a policy established in 1999, about TCAM that addressed the use of invasive and ingested TCAM therapies, $80 \%$ of the participants did not know that such a policy existed. However these findings show a striking degree of interest in TCAM training among the HCWs in HIV and AIDS (74.7\%). Most considered Ayurveda, aromatherapy, and massage. Therefore consideration must be given to providing TCAM education to the HCW so that they can offer accurate advice to patients about TCAM.

In respect to attitude towards TCAM, the results show that, 29, 6\% of the participants had a positive view of TCAM and $8.6 \%$ had negative views. Some of the participants were very skeptical about TCAM and did not have sufficient knowledge about TCAM, therefore most of the participants stated that they had neutral views about TCAM (28.4\%) and 33.3\% said they did not know about TCAM. The results suggests that the skepticisms may be due to the following factors: firstly there is no scientific evidence to prove that TCAM was safe and that more scientific validation is needed, This is supported by results in Lewith et al. (2001) who also suggested that TCAM must become a greater research priority and that TCAM should be subjected to more scientific testing. Secondly, HCWs in the HIV/AIDS clinic were more concerned about patients adhering to ARTs, they also want patients to test early and start their treatment early and there feel that use of TCAM will interfere. Therefore it is vital to establish possible synergy combinations of TCAM and conventional treatment for HIV, and to understand the mechanisms of action of TCAM therapies (Lui, 2007). Thirdly, HCWs in HIV/AIDS clinic felt that ARTs are lifelong and should not be mixed with other herbs. The reason for this may be that they are concerned with drug-herb interaction. It would appear that the role of TCAM in HIV/AIDS individuals needs to be researched further to provide clear guidelines on its benefits in the treatment HIV/AIDS.

With regards to personal use of TCAM majority of the HCWs stated that they do not use TCAM personally ( $78.3 \%$ female) and (66.7\% male). This may be due to lack of knowledge about TCAM, lack of trust in TCAM. These findings are similar to the findings of the study by Brown et al. (2007) which showed that the majority of the participants indicated that they rarely use TCAM (80\%) or even visited a TCAM practitioner (86\%).

Only a few participants (10.1\%) referred patient to TCAM professions, these results may be due to lack of knowledge and trust about TCAM. These results must be regarded with caution in view of the low response rate (50\%)

\section{Conclusion}

Consideration must, therefore, be given to providing enhanced resources and training for HCWs in TCAM so that they can begin to provide appropriate and needed information to patients and families about TCAM. Participants in this study had limited or little personal experience and professional experience with regards to TCAM. However participants showed a positive attitude towards TCAM and demonstrated high level of interest in learning about TCAM.

The low referral practice of HCWs to TCAM practitioners might have been influenced by poor knowledge of TCAM, as it would seem to be more appropriate to refer patients to the treatments that the HCWs are familiar with. Furthermore many concerns were raised by HCWs about TCAM such as lack of scientific evidence, drug-herb interaction, overdosing, drug resistance and poor adherence especially for HIV and AIDS patients who have to use ARTs for the rest of their lives

The conclusions are tempered by the low response rate. Although the results of this study are limited to the HIV and AIDS clinic in Durban public hospitals, the results of this study can give opportunity for other researchers who show interest in TCAM to undertake future studies in this as it is needed in South Africa. This preliminary work has laid the foundation for further examination of HCWs knowledge, attitudes and practices towards TCAM. This study has helped identify the interests and needs of HCWs with regards to TCAM. 


\section{Acknowledgements}

The authors wish to acknowledge financial support from the National Research Foundation (NRF) and the Department of Science and Technology (DST). The views expressed here reflect those of the authors and not the funders DST/NRF.

\section{References}

1. Achilles, R., et al. (1999). Complementary and Alternative Health Practices and Therapies: A Canadian Overview.

2. Botting, D. (1997). Review of literature on the effectiveness of reflexology. Complementary Therapies in Nursing and Midwifery. 3: 123-130.

3. Brolinson, P. G., et al. (2001). Nurses' perceptions of complementary and alternative medical therapies. Journal of Community Health. 26(3): 175-189.

4. Brown, J., et al. (2007). Complementary and alternative therapies: Survey of knowledge and attitudes of health professionals at a tertiary pediatric/women's care facility. Complementary Therapies in Clinical Practice. 13(3): 194-200.

5. $\quad$ Chandy, B. K. (2004). WHO-Facts Sheet. Kuwait Medical Journals. 36(3): 237-242.

6. Chez, R. A., et al. (2001). A survey of medical student's opinions about complementary and alternative medicine. American Journal of Obstetrics and Gynecology. 185: 754 - 757.

7. Dhalla, S., et al. (2006). Complementary and alternative medicine use in British Columbia- A survey of HIV positive people on antiretroviral therapy. Complementary Therapies in Clinical Practice. 12(4): 242-248.

8. Dekeyser, F. G., et al. (2001). Knowledge levels and attitudes of staff nurses in Israel towards complementary and alternative medicine. Journal of Advanced Nursing. 36: 41-48.

9. Gqaleni, N., et al. (2007). Traditional complementary medicine: Health Care Delivery. South African Health Review. $175-188$

10. Holroyd, E., et al. (2008). Belief and attitudes towards complementary medicine among registered nurses in Hong Kong. International Journal of Nursing Studies. 45: 1660-1666.

11. Lewith, G. T., et al. (2001). Attitudes to and use of complementary medicine among physicians in the United Kingdom. Complementary Therapies in Medicine. 9: 167-172.

12. London, A. S., et al. (2003). Use of alternative therapies among people in care for HIV in the United States. American Journal in Public Health. 93(6): 980-987.

13. Long, L., et al. (2001). Which complementary and alternative therapies benefit which condition? A survey of the opinion of 223 professional organizations. Complementary Therapies in Medicine. 9: 178-185.

14. Lui, J. (2007). The use of herbal medicines in early drug development for the treatment of HIV infections and AIDS. Expert Opinion Investing Drugs. 16(9): 1355-1364.

15. Risberg, T., et al. (2004). Knowledge of and Attitudes towards Complementary and Alternative Therapies national multicentre study of oncology professionals in Norway. European Journal of Cancer. 40(4): 529-535.

16. Truter, I. (2005). Knowledge and Perceptions of Pharmacy students towards training in complementary and alternative health care. Health South Africa Gesondheid. 10 (2).

17. Uzun, O. and Tan, M. (2004). Nursing students' opinions and knowledge about complementary and alternative medicine therapies. Complementary Therapies in Nursing and Midwifery. 10(4): 239-244.

18. World Health Organization. (2008). Factsheet 134: Traditional Medicine. Geneva.

19. White, P. (2000). What can general practice learn from complementary medicine? British Journal of General Practice. 50: 821-823.

20. Willison, K. D., et al. (2004). Complementary medicine and older people: past research and future directions. Complementary Therapies in Nursing and Midwifery. 10(2): 80-90. 